Research Article

\title{
Reaction Kinetics of Sodium Bentonite with Different Acid Systems: An Experimental Study
}

\author{
Yang Li $\mathbb{D}^{1},{ }^{1}$ Xiaoming Ni, ${ }^{1,2}$ Zheng Zhao $\mathbb{D}^{1},{ }^{1}$ Cixiang Yang, ${ }^{1}$ and Zhongcheng $\mathrm{Li}^{3}$ \\ ${ }^{1}$ School of Energy Science and Engineering, Henan Polytechnic University, Jiaozuo 454000, Henan, China \\ ${ }^{2}$ Collaborative Innovation Center of Coalbed Methane and Shale Gas for Central Plains Economic Region Henan Province, \\ Jiaozuo 454000, China \\ ${ }^{3}$ China United Coalbed Methane Co., Ltd., Beijing 100011, China
}

Correspondence should be addressed to Yang Li; 326675568@qq.com

Received 17 November 2019; Revised 6 February 2020; Accepted 2 April 2020; Published 21 April 2020

Academic Editor: Pedro M. Mancini

Copyright (c) 2020 Yang Li et al. This is an open access article distributed under the Creative Commons Attribution License, which permits unrestricted use, distribution, and reproduction in any medium, provided the original work is properly cited.

\begin{abstract}
Discovering the characteristics of the reaction kinetics of acid systems (hydrogen fluoride (HF), hydrochloric acid ( $\mathrm{HCl})$, and $\mathrm{CH}_{3} \mathrm{COOH}$ ) at different concentrations with sodium bentonite can provide experimental support for optimising formulations used in removing plugs through acidification. By utilising a spectrophotometer and acid-base titration, changes in contents of $\mathrm{Si}$, $\mathrm{Al}$, and $\mathrm{H}^{+}$concentration when sodium bentonite reacted with different acid systems $\left(\mathrm{HF}, \mathrm{HF}, \mathrm{HCl}\right.$, and $\left.\mathrm{HF}_{\text {and }} \mathrm{CH}_{3} \mathrm{COOH}\right)$ at different concentrations $(5 \%, 10 \%$, and $15 \%)$ for different reaction times $(1,2,4,8,12$, and $24 \mathrm{~h})$ at $45^{\circ} \mathrm{C}$ were measured. Based on this, a reaction kinetics model of $\mathrm{H}^{+}$was fitted and reaction mechanisms of $\mathrm{HF}$ with sodium bentonite after adding $\mathrm{HCl}$ and $\mathrm{CH}_{3} \mathrm{COOH}$ were analysed. The results demonstrated that the rate of dissolution of $\mathrm{Al}$ was high and the reaction reached equilibrium in $1 \mathrm{~h}$. Si showed a fast dissolution rate in the acid solution containing $\mathrm{HF}$. In an $\mathrm{HCl}+\mathrm{HF}+\mathrm{CH}_{3} \mathrm{COOH}$ acid system, at a concentration of $15 \%$, the greatest dissolution occurred, with a more stable dissolution rate and longer reaction time. Among the three acids tested, it was HF that mainly reacted with sodium bentonite, while the other two acids had weak reactions therewith. In the acid system containing HF, HF molecules reacted with sodium bentonite, rather than other forms, such as $\mathrm{H}^{+}$, $\mathrm{F}^{-}$, and $\mathrm{HF}_{2}^{-}$. The addition of $\mathrm{HCl}$ could promote the reaction, while $\mathrm{CH}_{3} \mathrm{COOH}$ inhibited the reaction. The research results provide experimental support for optimising the formulation of such acid solutions.
\end{abstract}

\section{Introduction}

Discovering the kinetic characteristics of reactions of different acid systems with clay minerals and carbonate minerals can provide accurate experimental parameters for formulation optimisation. At present, the research methods for kinetics of acid-rock reactions mainly include static and dynamic acid-rock reactions [1].

The research method of static acid-rock reaction kinetics is as follows: the static acid-rock reaction is used to measure changes in $\mathrm{Si}$ and $\mathrm{Al}$ elements concentration at different temperatures after different reaction times by placing reactants in acid solution, for example, put montmorillonite, illite, and kaolinite statically in HF, soil acid system, carbonic acid, and other solutions to test the changes in the concentration of $\mathrm{Si}$ and $\mathrm{Al}$ elements and calculate the reaction rate of $\mathrm{Si}$ and $\mathrm{Al}$ elements, moreover combining reaction kinetic equations to explore its dynamic characteristics [2-4]. This method has a simple experimental design and is easy to operate, but it cannot simulate the state of flow of acid solutions in formation.

The research methods of dynamic acid-rock reaction kinetics include rotating disk method and parallel plate method. The former is used to measure changes in $\mathrm{H}^{+}$ concentration at different temperatures and pressures and allows calculation of the reaction rate by rotating the core in an acid solution. This method can better simulate the environment for acidifying cores, while the differences in the core specimens can result in different experimental results owing to their innate variability in situ [5-7]. The latter is 
used to cut cores into rock plates of the same size, in which acid solution flows in the artificial cracks [8], thus measuring changes in $\mathrm{H}^{+}$concentration of acid solution at the outlet. It mainly focusses on the changes in flow conductivity of artificial cracks after the acid-rock reaction [9] and entails a relatively complex process for preparing the samples, and the test is slow.

The acidity of different acid solutions is different, which results in different reaction rates and degrees of reaction when different acid solutions react with clay minerals, and may also generate negative effects such as precipitation [10-12]. The aim of this study is to ascertain the changes in reaction rates of $\mathrm{HF}$ with sodium bentonite before and after adding hydrochloric acid $(\mathrm{HCl})$ and $\mathrm{CH}_{3} \mathrm{COOH}[13,14]$. Sodium bentonite reacted with different acid systems (HF, $\mathrm{HCl}$, and $\mathrm{CH}_{3} \mathrm{COOH}$ ) to measure changes in concentration and find the reaction kinetics; moreover, based on changes in $\mathrm{Si}$ and $\mathrm{Al}$ elements and $\mathrm{H}^{+}$content, reaction mechanisms were discussed, expecting to lay an experimental foundation for optimising the formulations of different acid solutions.

\section{Experimental}

The bentonite used in this reaction is produced by Lin'an District, Hangzhou City, Zhejiang Province. The sodiumbased bentonite produced in Lin'an, Zhejiang Province, was used, and its chemical composition was mainly aluminosilicate by XRD. The chemical equation was $\mathrm{M}_{v} \mathrm{Al}_{w} \mathrm{Si}_{x} \mathrm{O}_{y}(\mathrm{OH})_{z}$, where $\mathrm{M}$ was metal cations such as $\mathrm{Na}^{+}$ and $\mathrm{Mg}^{2+}$.

The different acid solutions are as follows: $\mathrm{HCl}, \mathrm{HF}$, $\mathrm{CH}_{3} \mathrm{COOH}$, and equally mixed $\mathrm{HCl}$ and $\mathrm{HF}, \mathrm{HF}$ and $\mathrm{CH}_{3} \mathrm{COOH}, \mathrm{HCl}$ and $\mathrm{CH}_{3} \mathrm{COOH}$, and $\mathrm{HCl}, \mathrm{HF}$, and $\mathrm{CH}_{3} \mathrm{COOH}$, and so on (expressed as $\mathrm{HCl}+\mathrm{HF}$, $\mathrm{HF}+\mathrm{CH}_{3} \mathrm{COOH}, \quad \mathrm{HCl}+\mathrm{CH}_{3} \mathrm{COOH}, \quad$ and $\mathrm{HCl}+\mathrm{HF}+\mathrm{CH}_{3} \mathrm{COOH}$ herein). Different acid solutions to $3 \%$ sodium bentonite solution are added; the concentrations are $5 \%, 10 \%$, and $15 \%$; solutions reacted at different temperatures ( $1 \mathrm{~h}, 2 \mathrm{~h}, 4 \mathrm{~h}, 8 \mathrm{~h}, 12 \mathrm{~h}$, and $24 \mathrm{~h})$, filtered, and tested the concentration of $\mathrm{Si}$ and $\mathrm{Al}$ elements and reaction kinetic parameters generated in the liquid phase [15].

\subsection{Measurement of Si and Al Element Concentration in the} Liquid Phase. The specific method is as follows: when different acid solutions with different concentrations $(5 \%, 10 \%$, and $15 \%)$ are reacted with $3 \%$ sodium bentonite to the test time $(1 \mathrm{~h}, 2 \mathrm{~h}, 4 \mathrm{~h}, 8 \mathrm{~h}, 12 \mathrm{~h}$, and $24 \mathrm{~h})$, the supernatant is pipetted from the reaction flask and filtered with a filter paper. The Shanghai Youke 721 spectrophotometer was used to calibrate the absorbance corresponding to different concentrations of $\mathrm{Si}$ and $\mathrm{Al}$ element solutions using ammonium molybdate spectrophotometry and chrome azurite spectrophotometry, and the standard curve corresponding to the absorbance was plotted [16] (Figure 1).

2.2. Test of Reaction Kinetic Parameters. According to the mass action principle, at constant temperature and pressure, the reaction rate is positively correlated with $m^{\text {th }}$ power product of the concentrations of each substance. Therefore, the reaction rate in the above experiment is expressed as follows:

$$
J=K C^{m},
$$

where $J, K$, and $C$ represent the chemical reaction rate $(\mathrm{mol} /$ $(\mathrm{L} \cdot \mathrm{s}))$ at a given time, the constant $\left((\mathrm{mol} / \mathrm{L})^{1-\mathrm{m}} / \mathrm{s}\right)$ of reaction rate, and the concentration $(\mathrm{mol} /(\mathrm{L} \cdot \mathrm{s}))$ in acidification at a given time, respectively, and $m$ indicates the reaction order and is dimensionless.

Taking the logarithm of both sides of equation (1),

$$
\lg J=\lg K+m \lg C \text {. }
$$

A logarithmic relationship diagram can be made, and the reaction order and reaction rate constant in the reaction kinetics can be obtained based on the slope and intercept of the diagram.

Therefore, it is necessary to test the acid concentration and $\mathrm{H}^{+}$reaction rate when the acid solution reaches the dissolution/analysis equilibrium at the initial $(5 \%, 7 \%, 10 \%$, $13 \%$, and $15 \%$ ) concentration and then calculate the reaction order and reaction rate. Constant, the reaction kinetic equation [17] is obtained. Among them, since the Si element in the sodium-based bentonite used in this experiment accounts for $71.79 \%$, the time for the acidification reaction to reach the dissolution/analysis equilibrium can be obtained according to the dissolution/analysis equilibrium time of the Si element in the liquid phase.

First, the acid concentration is tested after the reaction. The specific test method is as follows: for the sample that has reached the reaction time, $3 \mathrm{~mL}$ of the supernatant is filtered and taken and diluted with distilled water 10 times. $1 \mathrm{~mol} / \mathrm{L}$ $\mathrm{NaOH}$ solution is used for acid-base neutralization titration. The $\mathrm{pH}$ meter records the $\mathrm{pH}$ of the solution. When it shows a $\mathrm{pH}$ of 7.00 , the titration is completed. The volume of the $\mathrm{NaOH}$ solution is recorded, and the acid concentration after the reaction is calculated.

As $\mathrm{CH}_{3} \mathrm{COOH}$, $\mathrm{HF}$ was weak acid, it was not completely ionised in water, and its concentration could change with the consumption of $\mathrm{H}^{+}$in the experimental process. And $\mathrm{HF}$ and $\mathrm{SiO}_{2}$ could generate strong acid $\mathrm{H}_{2} \mathrm{SiF}_{6}$ (fluorosilicic acid) in water (formula (3)), which could interfere with the measurement of $\mathrm{H}^{+}$in liquid solution after reaction. By indirectly measuring the amount of remaining $\mathrm{HF}$ to calculate and exclude $\mathrm{H}^{+}$produced by fluorosilicic acid, the $\mathrm{H}^{+}$ concentration in the sample liquid phase that participates in the reaction is tested:

$$
\mathrm{SiO}_{2}+6 \mathrm{HF}=\mathrm{H}_{2} \mathrm{SiF}_{6}+2 \mathrm{H}_{2} \mathrm{O}
$$

The test method was as follows: for samples do not containing HF in the reactive acids, the acids solution concentration before the reaction is subtracted from the acid solution concentration after the reaction to obtain the $\mathrm{H}^{+}$ concentration changes during the sample reaction and calculate the reaction rate. For samples containing HF in reactive acids, a certain volume of supernatant was taken for an erosive experiment on a slide. According to changes in mass before and after erosion on the slide, the residual HF 


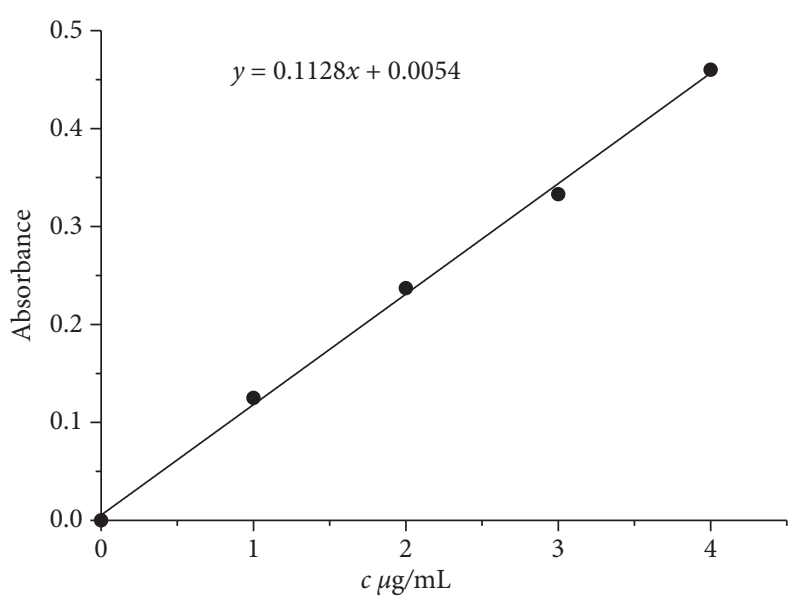

(a)

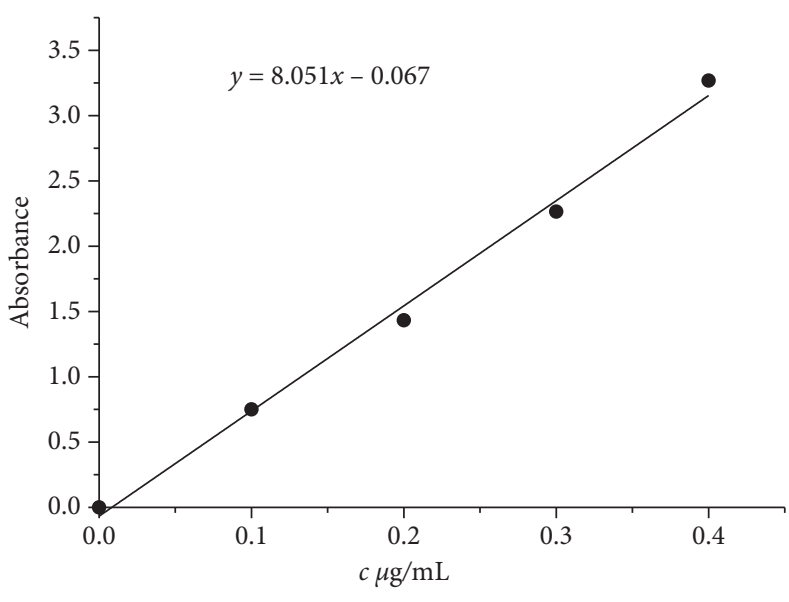

(b)

Figure 1: Standard curve of absorbance of (a) Si element and (b) Al element.

content after reaction of the samples was calculated and the amount of HF consumed in the reaction was obtained; furthermore, the $\mathrm{H}^{+}$content and concentration of $\mathrm{H}_{2} \mathrm{SiF}_{6}$ fluorosilicic acid produced by the sample were calculated. The acid solution concentration before the reaction is subtracted from the acid solution concentration after the reaction and the $\mathrm{H}^{+}$concentration in the generated $\mathrm{H}_{2} \mathrm{SiF}_{6}$ to obtain the $\mathrm{H}^{+}$concentration change during the sample reaction, and the reaction rate is calculated.

\section{Experimental Results and Analysis}

3.1. Analysis of the Changes in the Si and Al Elements in the Liquid Phase under Different Reaction Times. The changes in $\mathrm{Si}$ and $\mathrm{Al}$ contents after reaction of sodium bentonite with different acids at $45^{\circ} \mathrm{C}$ for different times are shown in the figure.

As presented in the Figures 2(a)-2(c), the dissolution of $\mathrm{Si}$ and $\mathrm{Al}$ elements in different acid solutions had the following characteristics:

(1) Effect of reaction time on dissolution

It can be seen from the figure that, with increasing reaction time, dissolution of $\mathrm{Si}$ rapidly rises in the first $2 \mathrm{~h}$, then slows down from 2 to $4 \mathrm{~h}$, and finally tends to be stable or grows slowly in the later stage of testing. Dissolution of Al rapidly increases in the first $1 \mathrm{~h}$ and shows fluctuations within a certain range thereafter.

(2) Effect of acid type and concentration on dissolution (1) Dissolution of $\mathrm{Si}$ element: the acid solution containing no HF has less dissolution amount than the acid solution containing HF. In acids types without $\mathrm{HF}$, the reaction will reach equilibrium at $1 \mathrm{~h}$ and will stabilize in the later stages. The order of dissolution amount is $\mathrm{HCl}>\mathrm{HCl}+\mathrm{CH}_{3} \mathrm{COOH}>$ $\mathrm{CH}_{3} \mathrm{COOH}$, and the amount of dissolution in a $5 \%$ acid solution is less than those in $10 \%$ and $15 \%$ acid solutions; however, there is a small difference in the amount of dissolution of $\mathrm{Si}$ in $10 \%$ and $15 \%$ acid solutions. In acids types containing HF, when using $\mathrm{HF}$ acidification, the concentration of 5\% concentration rose at $0 \sim 1 \mathrm{~h}$ and $10 \%$ and $15 \%$ concentration rose fastest at $0 \sim 2 \mathrm{~h}$; then, the rising rate decreased and reached the maximum dissolution amount at $4 \mathrm{~h}$, and the dissolution amount at $4 \sim 24 \mathrm{~h}$ gradually lowers and reaches equilibrium. When using $\mathrm{HF}+\mathrm{CH}_{3} \mathrm{COOH}$ acidification, the concentration of Si element increased slowly under different acid solution concentrations, the dissolution amount reached the maximum value in $4 \mathrm{~h}$, and the concentration did not decrease in the later period. When using $\mathrm{HCl}+\mathrm{HF}$ acidification, the increase rate of $\mathrm{Si}$ element concentration was greater than that of most other acid types. Under different concentrations, the dissolution rate gradually decreased at $0 \sim 1 \mathrm{~h}$ AND $1 \sim 2 \mathrm{~h}$, reached the maximum dissolution rate at $2 \sim 4 \mathrm{~h}$, and then stabilized. The dissolution amount is greater than all other acid types when 5\% and 10\% concentrations are acidified. Compared with 5\% concentration $\mathrm{HCl}$ and $\mathrm{HF}$, the mixed acid solution of $10 \% \mathrm{HCl}$ and $\mathrm{CH}_{3} \mathrm{COOH}$ has a higher Si element formation rate and a larger dissolution amount, indicating that $\mathrm{HCl}$ can promote the acidification of $\mathrm{HF}$. When using $\mathrm{HCl}+\mathrm{HF}+\mathrm{CH}_{3} \mathrm{COOH}$ acidification, the increase rate of $\mathrm{Si}$ element concentration was slightly lower than that of $\mathrm{HCl}, \mathrm{HF}$, and $\mathrm{HCl}+\mathrm{HF}$. The dissolution amount increased steadily at $0 \sim 4 \mathrm{~h}$, and it decreased slightly at $4 \sim 8 \mathrm{~h}$, reaching the maximum dissolution rate and becoming steady. The dissolution amount of $15 \%$ $\mathrm{HCl}+\mathrm{HF}+\mathrm{CH}_{3} \mathrm{COOH}$ is not much different from that of $10 \% \mathrm{HCl}+\mathrm{HF}$, but the reaction is more stable and the dissolution time is longer.

(2) Dissolution of Al element: the dissolution amount of $\mathrm{Al}$ element of different types of acids is different; $\mathrm{HF}, \mathrm{HF}+\mathrm{CH}_{3} \mathrm{COOH}, \mathrm{HCl}+\mathrm{CH}_{3} \mathrm{COOH}$, and $\mathrm{HCl}+\mathrm{HF}+\mathrm{CH}_{3} \mathrm{COOH}$ are larger, while $\mathrm{HCl}$, 

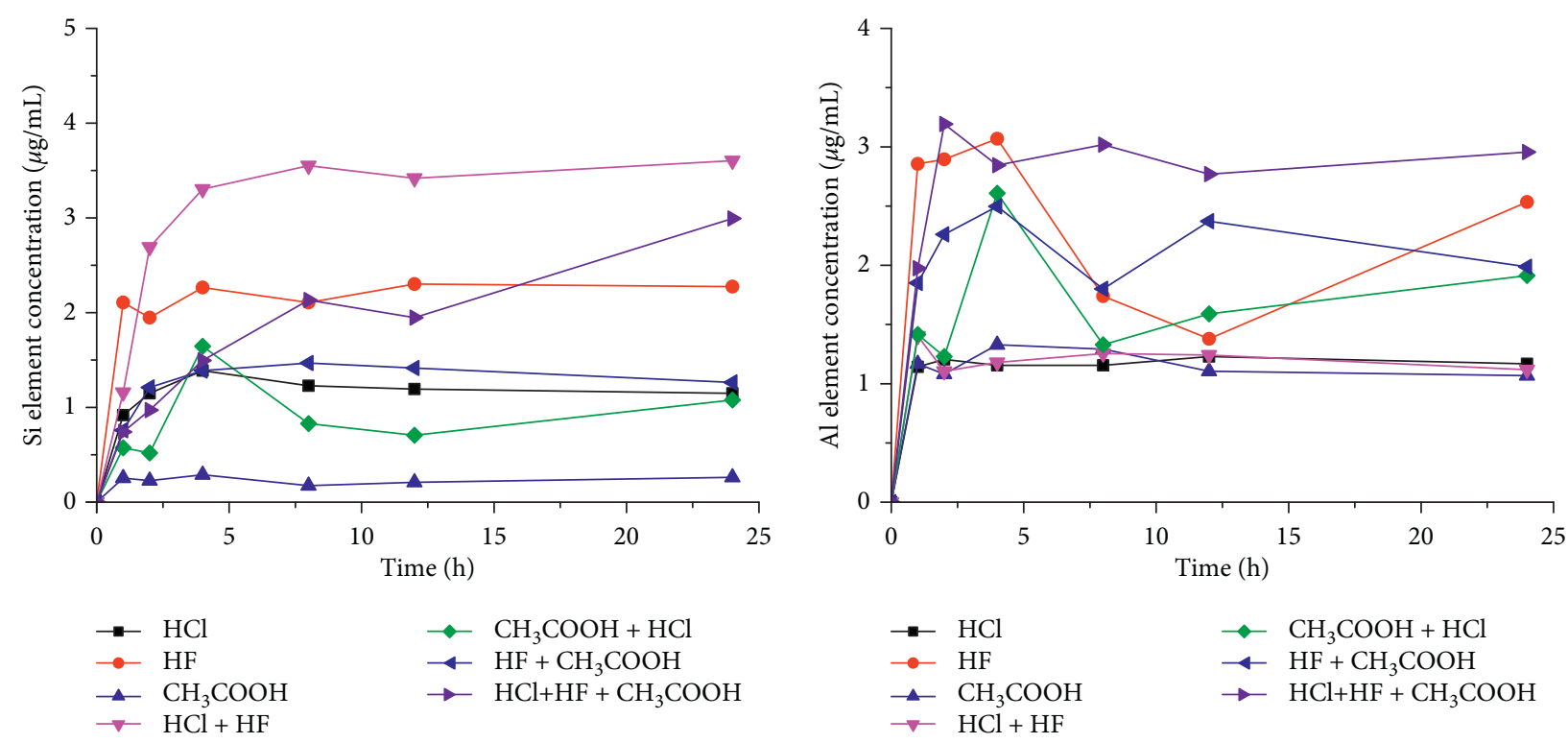

(a)
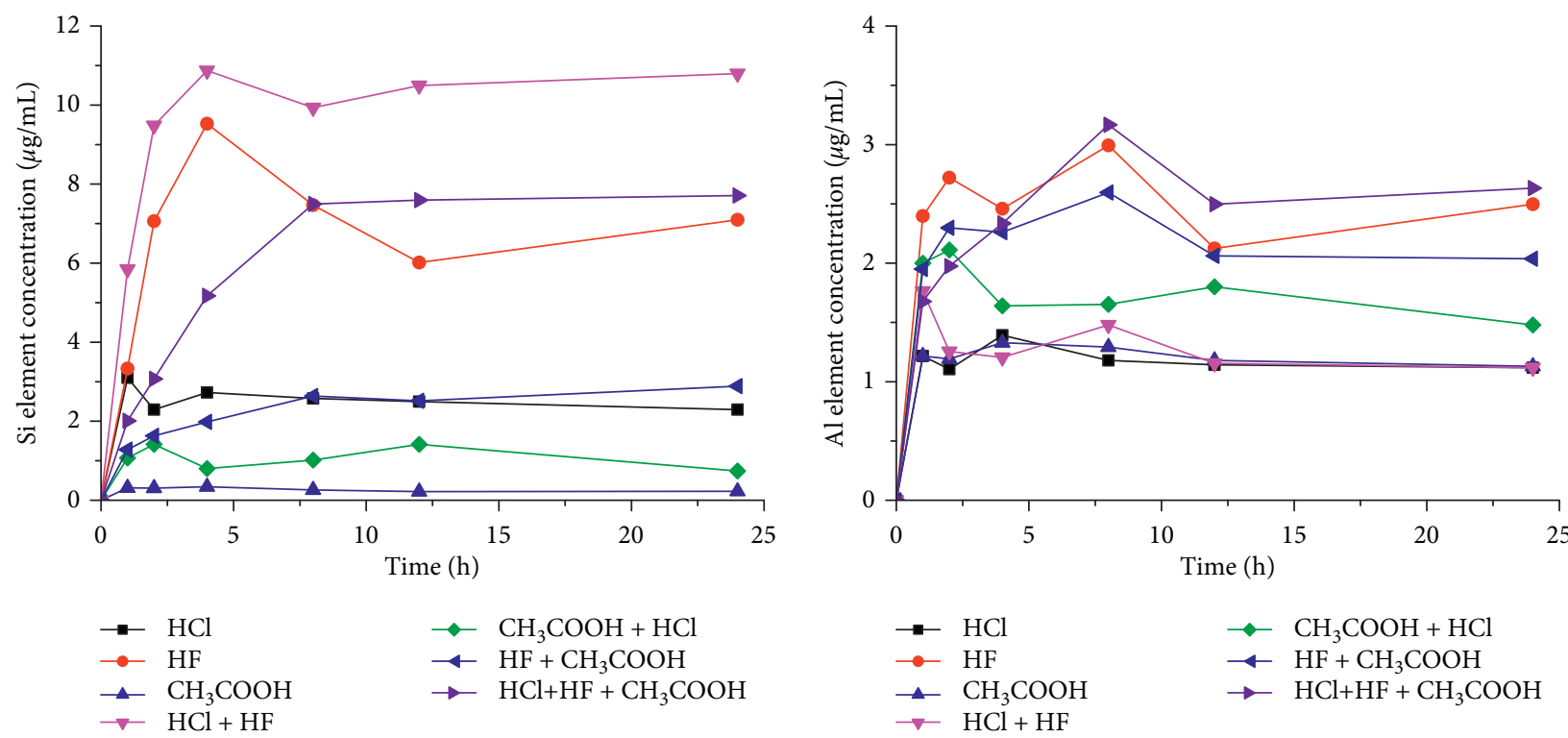

(b)

Figure 2: Continued. 

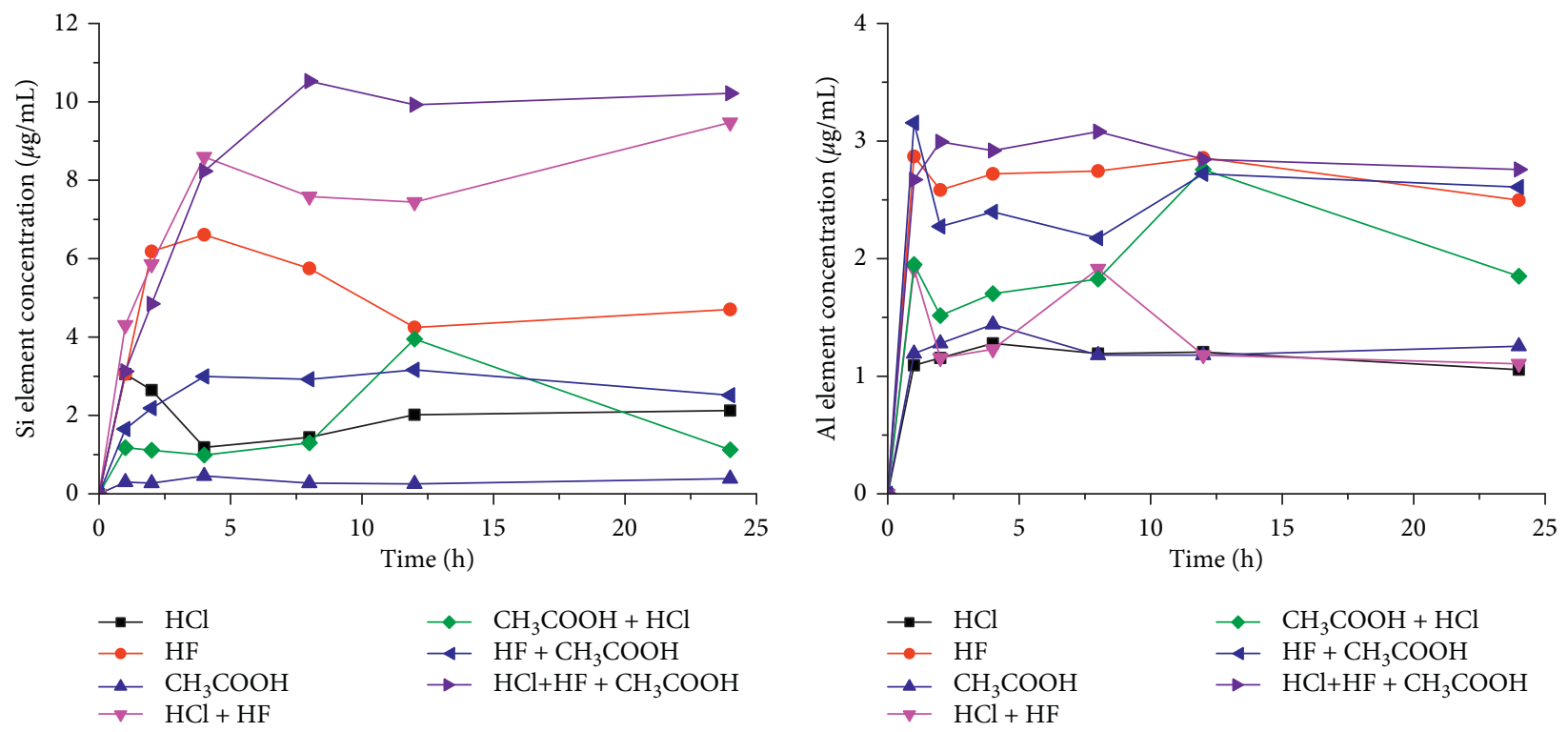

(c)

FIGURE 2: Variation of Si and Al elements with different concentrations of different acidified sodium bentonites overtime: (a) 5\% acid Si and $\mathrm{Al}$ elements change with time; (b) $10 \%$ acid Si and Al elements change with time; (c) $15 \%$ acid Si and Al elements change with time.

$\mathrm{CH}_{3} \mathrm{COOH}$, and $\mathrm{HCl}+\mathrm{HF}$ are smaller. The concentration of acid solution had little effect on the change in the amount of $\mathrm{Al}$ dissolution.

3.2. The Reaction Kinetics. At $45^{\circ} \mathrm{C}$, Table 1 shows the acid concentration and $\mathrm{H}^{+}$reaction rate data when the reaction between $\mathrm{HCl}, \mathrm{HF}, \mathrm{CH}_{3} \mathrm{COOH}$, and mixed acid with sodium bentonite reaches the dissolution/analysis equilibrium.

At $45^{\circ} \mathrm{C}$, the logarithmic linear curves of $\lg J$ and $\lg C$ for the reaction of $\mathrm{HCl}, \mathrm{HF}, \mathrm{CH}_{3} \mathrm{COOH}$, and mixed acids with sodium-based bentonite are shown in Figures 3(a) and 3(b), respectively.

According to the slope and intercept of the straight line in Figure 3, the reaction order and reaction rate constant of different types of acid and mixed acid acidified sodiumbased bentonite can be obtained. The calculation results are shown in Table 2.

As presented in Figure 3 and Table 2, among the three acids, it is HF that mainly reacts with sodium bentonite, while single $\mathrm{HCl}$, single $\mathrm{CH}_{3} \mathrm{COOH}$, and $\mathrm{HCl}+\mathrm{CH}_{3} \mathrm{COOH}$ only react slightly with sodium bentonite: when $\mathrm{HCl}$ is added to HF, the reaction order and the constant of reaction rate increase, thus promoting the reaction. The addition of $\mathrm{CH}_{3} \mathrm{COOH}$ causes the decrease of both reaction order and reaction rate constant.

3.3. Analysis. According to the above experimental research, it can be seen that HF reacts strongly with sodium bentonite. After the concentration of Si element reaches the maximum, it will decrease to a certain extent and then stabilize. After adding $\mathrm{HCl}, \mathrm{CH}_{3} \mathrm{COOH}$, and other acid solutions in $\mathrm{HF}, \mathrm{Si}$ element dissolves large differences in rate, dissolution, and reaction kinetics equations. Therefore, this article attempts to discuss the reaction mechanism of $\mathrm{HF}$ and sodium bentonite from the perspective of ionisation equilibrium and the effects of $\mathrm{HCl}$ and $\mathrm{CH}_{3} \mathrm{COOH}$ on the acidification of sodium bentonite by HF.

3.3.1. Reaction Mechanism of HF with Sodium Bentonite. HF solutions at a low concentration may have forms, such as $\mathrm{HF}$ molecules, $\mathrm{F}^{-}, \mathrm{HF}_{2}^{-}$, and $\mathrm{H}^{+}$[18], so it is necessary to know which form reacts with sodium bentonite. At $25^{\circ} \mathrm{C}$, there is an ionisation balance of each form as follows:

$$
\begin{gathered}
\mathrm{HF} \rightleftarrows \mathrm{H}^{+}+\mathrm{F}^{-} \mathrm{K}_{1}=\frac{\left[\mathrm{H}^{+}\right]\left[\mathrm{F}^{-}\right]}{[\mathrm{HF}]}=6.6 \times 10^{-4}, \\
2 \mathrm{HF} \rightleftarrows \mathrm{H}^{+}+\mathrm{HF}_{2}^{-} \mathrm{K}_{2}=\frac{\left[\mathrm{H}^{+}\right]\left[\mathrm{HF}_{2}^{-}\right]}{[\mathrm{HF}]^{2}}=2.2 \times 10^{-3},
\end{gathered}
$$

where $K_{n}(n=1,2)$ represents the constant of ionisation equilibrium; $\left[\mathrm{H}^{+}\right],\left[\mathrm{F}^{-}\right]$, and $\left[\mathrm{HF}_{2}^{-}\right]$indicate the concentrations $(\mathrm{mol} / \mathrm{L})$ of $\mathrm{H}^{+}, \mathrm{F}^{-}$, and $\left[\mathrm{HF}_{2}^{-}\right]$in the solution, respectively; and $[\mathrm{HF}]$ denotes the concentration $(\mathrm{mol} / \mathrm{L})$ of unionised HF molecules.

According to the Vant' Hoff equation, the equilibrium constants $K_{1}(T)$ and $K_{2}(T)$ of the reaction separately are given by the following equation:

$$
K_{n}(T)=K_{n} e^{\left[\Delta H_{n} / R\left(\left(1 / T_{0}\right)-(1 / T)\right)\right]}, \quad n=1,2,
$$

where $\Delta H_{n}(n=1,2)$ denotes the enthalpy change and its values in formulae (4) and (5) are $-3,210$ and $-2,080$ through reference to published data; $R$ denotes the ideal gas constant $\left(8.314472 \mathrm{~J} \cdot \mathrm{K}^{-1} \cdot \mathrm{mol}^{-1}\right)$; and $T_{0}$ and $T$ represent the reaction temperature and Kelvin temperatures at $0^{\circ} \mathrm{C}$, respectively.

$\mathrm{HF}$ in solution has a constant total mole number of fluorine, so 
TABLE 1: Statistics of experimental data on the reaction of different types of acids with sodium bentonite.

\begin{tabular}{|c|c|c|c|}
\hline Acid composition & The initial concentration (\%) & Amount of substance after reaction $(\mathrm{mol} / \mathrm{L})$ & Reaction speed $(\mathrm{mol} / \mathrm{s})$ \\
\hline \multirow{5}{*}{$\mathrm{HCl}$} & 5 & 0.518 & $3.137 \times 10^{-8}$ \\
\hline & 7 & 0.669 & $3.378 \times 10^{-8}$ \\
\hline & 10 & 0.945 & $4.147 \times 10^{-8}$ \\
\hline & 13 & 1.362 & $4.703 \times 10^{-8}$ \\
\hline & 15 & 1.882 & $5.794 \times 10^{-8}$ \\
\hline \multirow{5}{*}{$\mathrm{HF}$} & 5 & 0.330 & $3.511 \times 10^{-7}$ \\
\hline & 7 & 0.610 & $5.814 \times 10^{-7}$ \\
\hline & 10 & 0.733 & $6.456 \times 10^{-7}$ \\
\hline & 13 & 0.953 & $7.792 \times 10^{-7}$ \\
\hline & 15 & 1.799 & $1.334 \times 10^{-6}$ \\
\hline \multirow{5}{*}{$\mathrm{CH}_{3} \mathrm{COOH}$} & 5 & 0.921 & $9.563 \times 10^{-9}$ \\
\hline & 7 & 1.183 & $1.016 \times 10^{-8}$ \\
\hline & 10 & 1.505 & $1.126 \times 10^{-8}$ \\
\hline & 13 & 1.859 & $1.192 \times 10^{-8}$ \\
\hline & 15 & 2.390 & $1.272 \times 10^{-8}$ \\
\hline \multirow{5}{*}{$\mathrm{HCl}+\mathrm{HF}$} & 5 & 0.715 & $1.660 \times 10^{-7}$ \\
\hline & 7 & 0.793 & $1.715 \times 10^{-7}$ \\
\hline & 10 & 0.985 & $2.138 \times 10^{-7}$ \\
\hline & 13 & 1.410 & $2.801 \times 10^{-7}$ \\
\hline & 15 & 1.572 & $3.171 \times 10^{-7}$ \\
\hline \multirow{5}{*}{$\mathrm{HCl}+\mathrm{CH}_{3} \mathrm{COOH}$} & 5 & 0.610 & $3.536 \times 10^{-8}$ \\
\hline & 7 & 0.777 & $4.090 \times 10^{-8}$ \\
\hline & 10 & 1.197 & $4.861 \times 10^{-8}$ \\
\hline & 13 & 1.565 & $5.424 \times 10^{-8}$ \\
\hline & 15 & 1.938 & $6.165 \times 10^{-8}$ \\
\hline \multirow{5}{*}{$\mathrm{HF}+\mathrm{CH}_{3} \mathrm{COOH}$} & 5 & 0.550 & $3.478 \times 10^{-7}$ \\
\hline & 7 & 0.718 & $3.792 \times 10^{-7}$ \\
\hline & 10 & 0.937 & $4.320 \times 10^{-7}$ \\
\hline & 13 & 1.257 & $4.813 \times 10^{-7}$ \\
\hline & 15 & 1.599 & $5.516 \times 10^{-7}$ \\
\hline \multirow{5}{*}{$\mathrm{HCl}+\mathrm{HF}+\mathrm{CH}_{3} \mathrm{COOH}$} & 5 & 1.127 & $2.492 \times 10^{-7}$ \\
\hline & 7 & 1.346 & $2.905 \times 10^{-7}$ \\
\hline & 10 & 1.583 & $3.534 \times 10^{-7}$ \\
\hline & 13 & 1.855 & $4.206 \times 10^{-7}$ \\
\hline & 15 & 2.198 & $5.102 \times 10^{-7}$ \\
\hline
\end{tabular}

$$
[\mathrm{HF}]_{0}=[\mathrm{HF}]+\left[\mathrm{F}^{-}\right]+2\left[\mathrm{HF}_{2}^{-}\right],
$$

where $[\mathrm{HF}]_{0}$ denotes the initial concentration $(\mathrm{mol} / \mathrm{L})$ of $\mathrm{HF}$.
By sorting formulae (4) to (7), concentrations of different forms of HF in solution are given by

$$
\left\{\begin{array}{l}
{[\mathrm{HF}]=\frac{-\left(K_{1}(T)+\left[\mathrm{H}^{+}\right]\right)+\sqrt{\left(K_{1}(T)+\left[\mathrm{H}^{+}\right]\right)^{2}+8 K_{2}(T) \cdot\left[\mathrm{H}^{+}\right] \cdot[\mathrm{HF}]}}{4 K_{2}(T)},} \\
{\left[\mathrm{F}^{-}\right]=\frac{K_{1}(T) \cdot[\mathrm{HF}]}{\left[\mathrm{H}^{+}\right]},} \\
{\left[\mathrm{HF}_{2}^{-}\right]=\frac{K_{2}(T) \cdot[\mathrm{HF}]^{2}}{\left[\mathrm{H}^{+}\right]} .}
\end{array}\right.
$$

When the $\mathrm{H}^{+}$concentration in the solution changes, the reaction equilibrium shifts and concentrations of different forms of $\mathrm{HF}$ in the solution change: the concentration ratio is used to represent the changes in concentrations in different forms under different $\mathrm{H}^{+}$concentrations, as demonstrated in Figures 4(a)-4(c). 


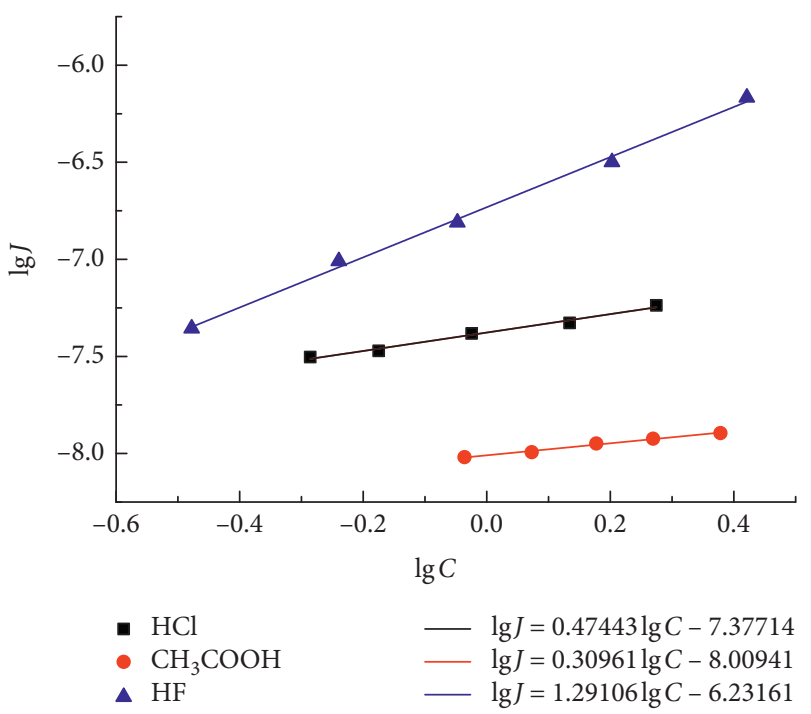

(a)

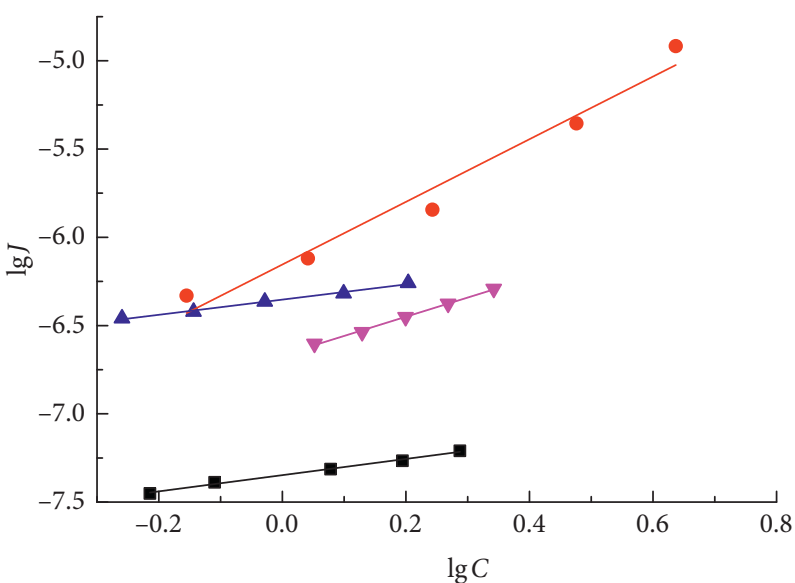

- $\mathrm{HCl}+\mathrm{CH} 3 \mathrm{COOH}-\lg J=0.45981 \lg C-7.3475$

- $\mathrm{HF}+\mathrm{HCl}-\lg J=1.77476 \lg C-6.15424$

\ $\mathrm{HF}+\mathrm{CH}_{3} \mathrm{COOH}-\lg J=0.43035 \lg C-6.35298$

$\nabla \mathrm{HCl}+\mathrm{HF}+\mathrm{CH}_{3} \mathrm{COOH}-\operatorname{llg} J=1.08723 \lg C-6.66752$

(b)

FIGURE 3: The relationship between the reaction rate of different acid solutions and sodium bentonite and the logarithm of multicomponent acid concentration: (a) logarithmic relationship between single acid and sodium bentonite; (b) logarithmic relationship between multicomponent acid and sodium bentonite.

TABle 2: Statistics of experimental results of acidified sodium bentonite in different acid systems.

\begin{tabular}{|c|c|c|c|}
\hline Acid composition & Reaction order & Reaction rate constant & Reaction kinetic equation \\
\hline $\mathrm{HCl}$ & 0.47443 & $4.19624 \times 10^{-8}$ & $J=4.19624 \times 10^{-8} C^{0.47443}$ \\
\hline $\mathrm{HF}$ & 1.29106 & $5.86665 \times 10^{-7}$ & $J=5.86665 \times 10^{-7} C^{1.29106}$ \\
\hline $\mathrm{HAC}$ & 0.30961 & $9.78566 \times 10^{-9}$ & $J=8.323 \times 10^{-7} C^{0.77913}$ \\
\hline $\mathrm{HCl}+\mathrm{HF}$ & 1.77476 & $7.01068 \times 10^{-7}$ & $J=7.01068 \times 10^{-7} C^{1.77476}$ \\
\hline $\mathrm{HCl}+\mathrm{CH}_{3} \mathrm{COOH}$ & 0.45984 & $4.49262 \times 10^{-8}$ & $J=4.49262 \times 10^{-8} C^{0.45984}$ \\
\hline $\mathrm{HF}+\mathrm{CH}_{3} \mathrm{COOH}$ & 0.43035 & $4.43629 \times 10^{-7}$ & $J=4.43629 \times 10^{-7} C^{0.43035}$ \\
\hline $\mathrm{HCl}+\mathrm{HF}+\mathrm{CH}_{3} \mathrm{COOH}$ & 1.08723 & $2.15021 \times 10^{-7}$ & $J=2.15021 \times 10^{-7} C^{1.08723}$ \\
\hline
\end{tabular}

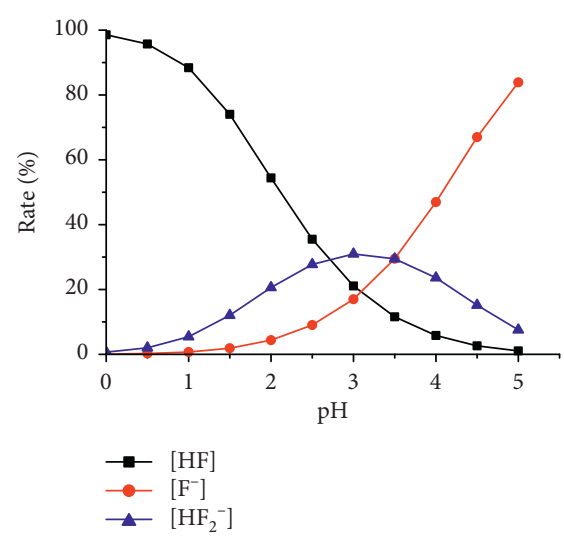

(a)

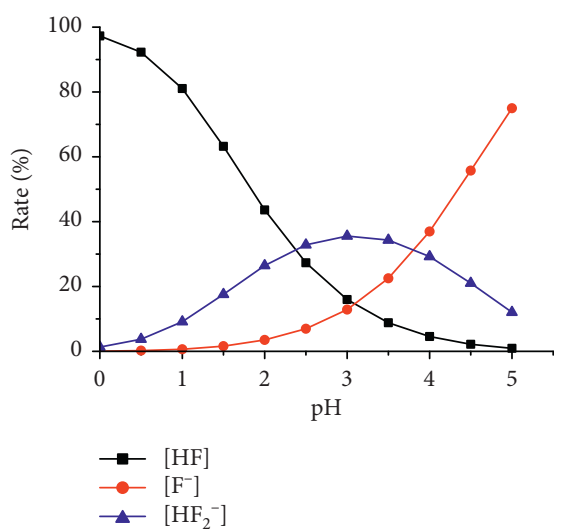

(b)

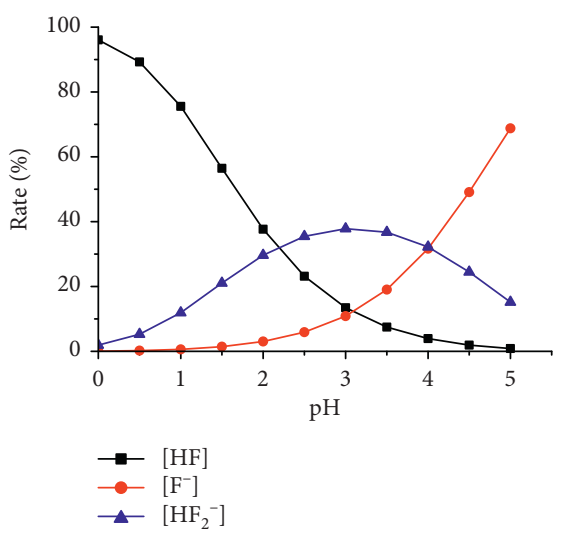

(c)

FIGURE 4: Variation in the proportion of different bodies in different concentrations of HF solution with pH: (a) 5\% concentration HF; (b) $10 \%$ concentration HF; (c) $15 \%$ concentration HF. 
TABLE 3: Changes in $\mathrm{pH}$ of sodium bentonite and different concentrations of $\mathrm{HF}$ at different reaction times.

\begin{tabular}{lccr}
\hline Time (h) & & HF concentration & \\
& $5 \%$ & $10 \%$ & $15 \%$ \\
\hline 1 & 3.39 & 3.63 & 1.98 \\
2 & 3.41 & 3.20 & 2.65 \\
4 & 3.43 & 3.21 & 3.11 \\
8 & 3.43 & 3.20 \\
\hline
\end{tabular}

It can be seen from the figure that, when $\mathrm{pH}<2$, mainly $\mathrm{HF}$ molecules are present in the solution and the amount thereof gradually decreases with increasing $\mathrm{pH}$. When $\mathrm{pH}>3$, there are few $\mathrm{HF}$ molecules present and the $\mathrm{F}^{-}$ content gradually increases in an exponential form, while the $\mathrm{HF}_{2}^{-}$content first increases and then decreases. At a $\mathrm{pH}$ of 3 , the $\mathrm{HF}_{2}^{-}$content is maximised and then decreases thereafter.

In comparison with Figure 2, when sodium bentonite reacts with $\mathrm{HF}$ solution for $1 \sim 2 \mathrm{~h}$, the rate of dissolution of $\mathrm{Si}$ is the fastest. At that moment, HF molecules in the solution dominate. As the $\mathrm{pH}$ increases to 3.11 to 3.43 , the amount of dissolution of Si elements remains unchanged. In this case, $\mathrm{F}^{-}$and $\mathrm{HF}_{2}^{-}$are mainly found in the solution, indicating that $\mathrm{HF}$ molecules mainly react with sodium bentonite. Changes in $\mathrm{pH}$ during the reaction of sodium bentonite with $\mathrm{HF}$ of different concentrations over different times are demonstrated in Table 3.

Therefore, there are three reactions between sodium bentonite and HF solution: the first is a reaction with $\mathrm{HF}$ molecules to generate $\mathrm{H}_{2} \mathrm{SiF}_{6}$, as shown in formula (1), because the resulting $\mathrm{H}_{2} \mathrm{SiF}_{6}$ is easily decomposed into $\mathrm{HF}$ molecules, and the second reaction involves decomposition of $\mathrm{HF}$ by $\mathrm{H}_{2} \mathrm{SiF}_{6}$ that further reacts with sodium bentonite and $\mathrm{H}_{2} \mathrm{SiF}_{6}$ reacts with metal cations to form a precipitate. In the third reaction, the aluminium-fluoride complexes generated in the first two reactions continue to react with aluminosilicate compounds present to generate fluorinecontaining complexes. When the $\mathrm{pH}$ reaches 3.04 to 3.48 , the reaction stops.

The second and third reactions of sodium bentonite with HF solution can explain the reason why the dissolution amount of Si element reaches a maximum after HF acidification in Figure 2 and then stabilizes.

\subsubsection{Effects of $\mathrm{HCl}$ and $\mathrm{CH}_{3} \mathrm{COOH}$ on $\mathrm{HF}$-Acidified Sodium} Bentonite. Aluminosilicate in sodium bentonite is expressed as $\mathrm{M}_{v} \mathrm{Al}_{w} \mathrm{Si}_{x} \mathrm{O}_{y}(\mathrm{OH})_{z}$, where $\mathrm{M}$ represents a metal cation. In aluminosilicate, there are covalent bonds, such as $\mathrm{Si}-\mathrm{O}, \mathrm{Si}-$ $\mathrm{OH}, \mathrm{Al}-\mathrm{O}$, and $\mathrm{Al}-\mathrm{OH}$ and ionic bonds between metal cations (such as $\mathrm{Na}^{+}, \mathrm{Ca}^{2+}, \mathrm{Mg}^{2+}$, and $\mathrm{Fe}^{2+}$ ) and aluminosilicate anions. Covalent bonds and ionic bonds in sodium bentonite can react with $\mathrm{HF}$, and the strength of a majority of such covalent bonds is higher than that of the ionic bonds present. Breaking of covalent bonds is critical for acidifying sodium bentonite with HF [19] and the rate at which these bonds are broken determines the reaction rate.

Through comparison with dissolution rates and amounts of $\mathrm{Si}$ in $\mathrm{HF}, \mathrm{HCl}+\mathrm{HF}$, and $\mathrm{HF}+\mathrm{CH}_{3} \mathrm{COOH}$ solutions, the addition of $\mathrm{HCl}$ is found to promote the reaction between $\mathrm{HF}$ and sodium bentonite, while $\mathrm{CH}_{3} \mathrm{COOH}$ inhibits the reaction between them. The difference between promotion and inhibition is caused by changes in $\mathrm{H}^{+}$concentration in the solution. The reason is as follows: $\mathrm{HCl}$ is a strong acid and can be completely ionised in water, while the ionisation constant of $\mathrm{CH}_{3} \mathrm{COOH}$ is smaller than that of $\mathrm{HF}$ at the same temperature. $\mathrm{H}^{+}$(being without electrons) easily reacts with oxygen in lattice bonds of minerals to form intermediate products. Moreover, $\mathrm{H}^{+}$has strong field polarisation, thus making intermediate products unstable, so that the reaction occurs more easily.

By adding $5 \% \mathrm{HF}$ of $30 \mathrm{~mL}$ to the samples of sodium bentonite, the $\mathrm{pH}$ is adjusted to $0.3,0.4$, and 0.5 using diluted $\mathrm{HCl}$, so as to calculate dissolution rates at different times (1, 2 , and $4 \mathrm{~h})$. The experimental results are presented in Figure 5 .

According to the calculation in Table 4, when the $\mathrm{pH}$ is between 0.3 and 0.4 , the rate of change in the distribution (by proportion) of HF in the solution is $0.587 \%$. Furthermore, rates of change in dissolution rates at 1 and $4 \mathrm{~h}$ are $3 \%$ and $3.06 \%$, respectively. When the $\mathrm{pH}$ is between 0.4 and 0.5 , the rate of change in the distribution (by proportion) of HF in the solution is $0.59 \%$ and those of the rates of dissolution are, separately, $1.37 \%$ and $2.21 \%$ at 1 and $4 \mathrm{~h}$. This indicates that the addition of $\mathrm{HCl}$ to the solution exerts no influence on the proportional distribution of $\mathrm{HF}$, while the dissolving capacity of $\mathrm{HF}$ increases significantly with increasing $\mathrm{H}^{+}$ concentration.

At the same temperature, the degree of ionisation of $\mathrm{CH}_{3} \mathrm{COOH}$ is lower than that of HF. The addition of $\mathrm{CH}_{3} \mathrm{COOH}$ to the $\mathrm{HF}$ solution increases the $\mathrm{pH}$ of the solution while reducing its $\mathrm{H}^{+}$concentration. This results in HF molecules in the solution shifting towards the direction of ionising $\mathrm{F}^{-}$and $\mathrm{HF}_{2}^{-}$and their concentration decreases, thus reducing the rate of reaction.

3.3.3. Work That Can Be Continued in the Future. In the mixed acid, only different kinds of acids were mixed in equal proportions and the results were discussed under ideal conditions, and the effect of temperature on the reaction was not considered. In the next step, based on the research in this paper, experiments will be carried out with different proportions of mixed acids at different temperatures. Analyzing the effect of different proportions of acid on the reaction rate, the effect of the product's isoionic effect on the reaction rate, and the effect of temperature on the reaction, the reaction activation energy is calculated and the change in $\mathrm{H}^{+}$ concentration is observed. 


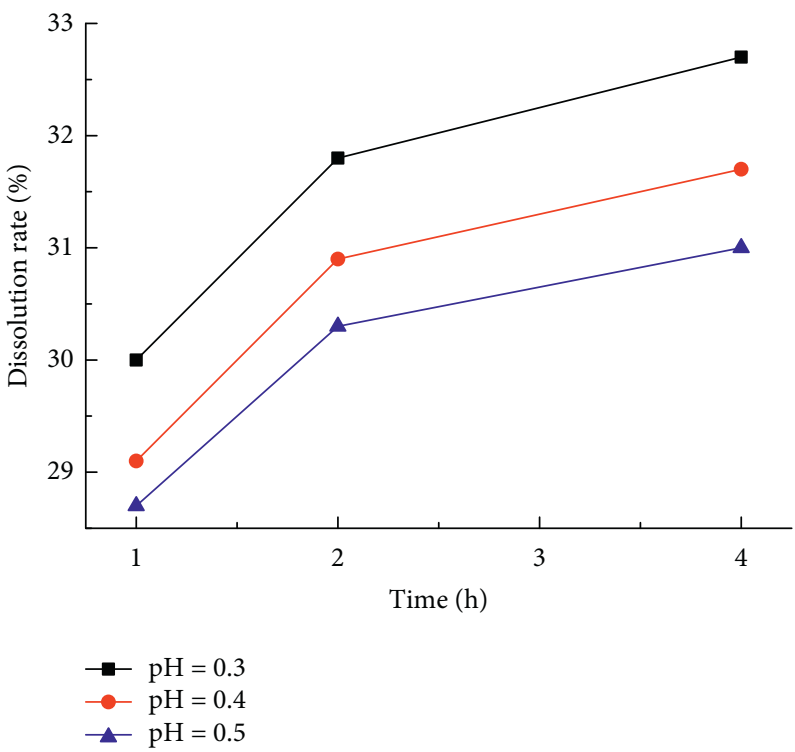

FIgURE 5: Dissolution rate of HF to sodium bentonite under different $\mathrm{pH}$ conditions.

TABLE 4: The relationship between the proportion of $\mathrm{HF}$ in different $\mathrm{pH}$ values and the range of dissolution rate at different times.

\begin{tabular}{lccc}
\hline $\mathrm{pH}$ interval & HF distribution ratio & $1 \mathrm{~h}$ dissolution rate variation range & 4h dissolution rate variation range \\
\hline $0.3 \sim 0.4$ & $0.9686 \sim 0.9629$ & $30 \sim 29.1$ & $32.7 \sim 31.7$ \\
$0.4 \sim 0.5$ & $0.9629 \sim 0.9573$ & $29.1 \sim 28.7$ & $31.7 \sim 31$ \\
\hline
\end{tabular}

\section{Conclusions}

The reaction between different acid systems and sodium bentonite was analysed, and the following conclusions are drawn:

(1) By conducting reaction experiments on different acid systems ( $\mathrm{HCl}, \mathrm{HF}, \mathrm{CH}_{3} \mathrm{COOH}$, and mixed acids with different concentrations of 5\%,10\%, and $15 \%$ ) with sodium bentonite, changes in the rate and amount of dissolution of $\mathrm{Si}$ and $\mathrm{Al}$ were obtained. The results demonstrated that the amount of dissolution of $\mathrm{Si}$ in acid solutions containing HF rapidly increased, slowly increased, and then tended to be stable thereafter. The amount of dissolution of $\mathrm{Si}$ in acid solutions without HF was lower and reached a maximum within $1 \mathrm{~h}$. The amounts of dissolution of Si in $10 \%$ and $15 \%$ acid solutions were similar. Al was quickly dissolved out in the first hour and then the amount of dissolution fluctuated within a certain range thereafter. The concentration of the acid solution exerted little influence on changes in the amount of dissolution of $\mathrm{Al}$.

(2) The reaction kinetics equations for the $\mathrm{H}^{+}$changes in seven acid types and sodium bentonite were calculated. The results showed that the main HF molecules reacted with sodium bentonite, and the single $\mathrm{HCl}$, $\mathrm{CH}_{3} \mathrm{COOH}$ and $\mathrm{HCl}+\mathrm{CH}_{3} \mathrm{COOH}$ reacted slightly with sodium bentonite.
(3) The reaction mechanism of sodium-based bentonite with $\mathrm{HF}$ and multicomponent acid and the reasons for the influence of $\mathrm{HCl}$ and $\mathrm{CH}_{3} \mathrm{COOH}$ on $\mathrm{HF}$ and sodium-based bentonite were revealed. The results show that there are three reactions between sodium bentonite and $\mathrm{HF}$ solution; one reaction reacts with $\mathrm{HF}$ to form $\mathrm{H}_{2} \mathrm{SiF}_{6}$, and the second is that $\mathrm{H}_{2} \mathrm{SiF}_{6}$ decomposes $\mathrm{HF}$ molecules to further react with it. The third reaction is the first two generations of fluorine. The aluminum complex continues to react with the aluminosilicate. The reaction with sodium bentonite is mainly HF molecules; the reaction is inhibited by adding $\mathrm{CH}_{3} \mathrm{COOH}$, and $\mathrm{HCl}$ is added to promote the reaction.

\section{Data Availability}

The data used to support the findings of this study are included within the article.

\section{Conflicts of Interest}

The authors declare that there are no conflicts of interest.

\section{Authors' Contributions}

Xiaoming Ni conceptualized the study, investigated the study, planned for resources, reviewed and edited the article, did project administration, and obtained funding 
acquisition. Yang Li was involved in methodology, curated the study, and wrote the original draft. Zhongcheng Li performed formal analysis and supervised the study. Zheng Zhao and Cixiang Yang validated the study. Zheng Zhao was responsible for visualization.

\section{Acknowledgments}

The research was supported by the Major Oil and Gas Special Project (2017ZX05064-003-001), the Ministry of Education Innovation Team Development Support Program (IRT_16R22), the National Natural Science Foundation of China (41872174), and the Central Plains Economic Zone Coal Seam (Shale) Gas Henan Collaborative Innovation Center.

\section{References}

[1] Y. Zhu, "Overview of experimental methods of acid rock reaction kinetics," Inner Mongolia Petrochemical Industry, vol. 33, no. 10, pp. 23-25, 2008.

[2] R. Gdanski, "Kinetics of the secondary reaction of HF on alumino-silicates," in Proceedings of the International Symposium on Oilfield Chemistry, Houston, TX, USA, February 1997.

[3] H. Guo, Y. Wang, X. Ni et al., "Digestion kinetics analysis of silicon and aluminum during kaolinite-water- $\mathrm{CO}_{2}$ interaction," Journal of China University of Mining \& Technology, vol. 45, no. 3, pp. 591-596, 2016.

[4] X. Ni, Y. Yu, Y. Wang et al., "Dissolution kinetics of $\mathrm{Si} / \mathrm{Al}$ elements of illites in carbonic acid solutions," Natural Gas Industry, vol. 34, no. 8, pp. 20-26, 2014.

[5] N. Qi, X. Sun, J. Fan et al., "The key problem and progress of acid-rock reaction dynamics," Science Technology and Engineering, vol. 19, no. 7, pp. 1-6, 2019.

[6] K. C. Taylor, H. A. Nasr-EI-Din, and S. Mehta, "Anomalous acid reaction rates in carbonate reservoir rocks," SPE, vol. 11, no. 4, pp. 488-496, 2006.

[7] A. I. Rabie, A. M. Gomaa, and H. A. Nasr-El-Din, "Determination of reaction rate of in-situ gelled acids with calcite using the rotating disk apparatus," in Proceedings of the SPE Production and Operations Conference and Exhibition, Tunis, Tunisia, June 2010.

[8] H. Yoo, Y. Kim, W. Lee, and J. Lee, "An experimental study on acid-rock reaction kinetics using dolomite in carbonate acidizing," Journal of Petroleum Science and Engineering, vol. 168, pp. 478-494, 2018.

[9] L. Qin, Exploration on A New Lab Method of Simulation of High-Viscosity Acid-Rock Reaction, Chengdu University of Technology, Chengdu, China, 2010.

[10] J. C. Labrid, "Thermodynamic and kinetic aspects of argillaceous sandstone acidizing," Society of Petroleum Engineers Journal, vol. 15, no. 2, pp. 117-128, 1975.

[11] R. Gdanski, "Kinetics of tertiary reactions of hydrofluoric acid on aluminosilicates," SPE Production \& Facilities, vol. 13, no. 2, pp. 75-80, 1998.

[12] R. D. Gdanski, "Kinetics of the secondary reaction of HF on alumino-silicates," SPE Production \& Facilities, vol. 14, no. 4, pp. 260-268, 1999.

[13] M. Buijse, Peter de Boer, B. Breukel, and G. Burgos, "Organic acid in carbonate acidizing," SPE Production \& Facilities, vol. 19, no. 3, pp. 128-134, 2004.
[14] E. P. Da Motta, A. D. Hill, and K. Sepehrnoori, "Selective matrix acidizing of horizontal wells," SPE Production \& Facilities, vol. 10, no. 3, pp. 157-164, 1995.

[15] Yi Guo, P. Liu, S. Wu et al., "The study of influential factors on acid rock reaction kinetics experiment," Journal of Chongqing University of Science and Technology (Natural Sciences Edition), vol. 16, no. 5, pp. 17-19, 2014.

[16] C. Zhong, G. Chai, L. Ma et al., "Determination of silicon and aluminum concentrations in reaction mixture of alkaline with reservoir rock minerals and influences of polymer and surfactant," Oilfield Chemistry, vol. 20, no. 4, pp. 360-362, 2003.

[17] H. Yonghong, X. Yang, S. Guo et al., "Research on parameters of acid rock rraction kinetics and its application," Xinjiang Oil \& Gas, vol. 13, no. 1, pp. 59-62+4, 2017.

[18] Y. Hekim and H. S. Fogler, "Acidization-VI: on the equilibrium relationships and stoichiometry of reactions in mud acid," Chemical Engineering Science, vol. 32, no. 1, pp. 1-9, 1977.

[19] F. Yanlin, Study on Reaction Kinetics of HCI/HF System and Sandstone Mineral, Southwest Petroleum University, Chengdu, China, 2015. 